\title{
Knowledge about HIV and AIDS among Young Women
}

\author{
Catherine M. Ngoma' ${ }^{1}$, Janetta Roos $^{2}$, Seter Siziya ${ }^{3}$ \\ ${ }^{1}$ Department of Nursing Sciences, School of Medicine, University of Zambia, Lusaka, Zambia \\ ${ }^{2}$ Department of Health Studies, University of South Africa, Pretoria, South Africa \\ ${ }^{3}$ Department of Community Medicine, School of Medicine, University of Zambia, Lusaka, Zambia \\ Email: catherinengoma@yahoo.com
}

Received 12 May 2015; accepted 26 June 2015; published 30 June 2015

Copyright (C 2015 by authors and Scientific Research Publishing Inc.

This work is licensed under the Creative Commons Attribution International License (CC BY). http://creativecommons.org/licenses/by/4.0/

\section{(c) (i) Open Access}

\begin{abstract}
HIV and AIDS are a major health concern among women worldwide. It is important that women especially youths are educated about HIV and AIDS because they represent a window of opportunity for reversing HIV rates if effective prevention programs can reach them before they engage in risky sexual behaviour. Women are more vulnerable to HIV infection than men and play a central role in the concept of the family, in nurturing, protecting, and caring for the family. The aim of the study was to explore HIV and AIDS knowledge among young women. A qualitative exploratory approach using focus group discussions was used and content analysis was used to interpret the data. A total of 8 focus group discussions were conducted two study sites intervention and control site. The analysis revealed 6 themes namely definition of HIV and AIDS, seriousness of HIV and AIDS in the community, signs and symptoms, transmission of HIV, cure for HIV and AIDS and prevention. The findings showed that some participants had knowledge deficit on HIV and AIDS, therefore continued community sensitisation is essential.
\end{abstract}

\section{Keywords}

Knowledge, HIV, AIDS, Young Women

\section{Introduction}

This study is part of a larger study that is designed to explore sexual behaviour and HIV and AIDS knowledge among rural young women.

HIV and AIDS has become one of the major health problems affecting people around the globe. More than 
40.3 million people were living with HIV in 2005 [1]. It is estimated that 4.9 million became newly infected with HIV and an estimated 3.1 million lost their lives to AIDS [2].

In Zambia, women have not been spared by HIV and AIDS scourge. About $18 \%$ of women are more likely to be HIV positive than men [3]. The national sentinel surveillance at selected sites countrywide has been used to monitor HIV prevalence among pregnant women and the trends from 1994 to 2002 indicate a slight variation from $20 \%$ in 1994 to $18.6 \%$ in 1998 and $19.1 \%$ in 2002. This percentage of HIV positive women that will transmit the virus to their babies is estimated to be $39 \%$ and this translates into 30,000 - 40,000 babies born with HIV infection every year in Zambia [3]. In addition, HIV prevalence is five times higher among girls under age 18 as young girls are preyed upon by older men including their guardians or caretakers [4].

As more and more women are getting infected with HIV, a large number of infants are born with the infection and children who are born without HIV become orphans at an early age and end up as destitute [1]. This is because women are central in the concept of the family, in nurturing, protecting and caring. Women have complex relationships and structures in their daily lives and sophisticated and subtle responsibilities and commitments [5]. Their demise, as a result of HIV and AIDS, will increasingly cause instability in communities where the disease is prevalent. Women are more vulnerable to HIV infection than men due to various factors such as socio-economic status, biological influences, sexual practices and epidemiological factors [5].

This article presents findings from qualitative study conducted in Zambia to assess HIV and AIDS knowledge among young women aged 15 - 24 years old. Findings from this study are used to design a tailored educational campaign focused on HIV and AIDs risk reduction

\section{Method}

A qualitative research design is used for this study. Qualitative research is concerned with individual situations or experiences making use of non-numerical data. In both Phases I and III the researcher collected data using Focus Group Discussions (FGDs). FGDs offered an opportunity for individuals to exchange ideas and validate experiences [6].

\subsection{Target Population}

Homogenous samples of women were selected from the villages within the two hospitals' catchment areas and were sampled in the same proportions from the intervention and comparison sites. The women were selected on the basis of gender, age and residence to both experimental and control groups. It was assumed that the above mentioned characteristics of the study subjects might affect the study outcome. By using a sample of homogenous subjects, the researcher has used a step of control [7].

\subsection{Interviews}

Data was collected using focus group discussions and eight FDGs were conducted, 4 each with the intervention and control participants. Each group comprised about 6 to 12 respondents with similar characteristics. The respondents were selected on the basis of age, gender and residence. The researcher designed a topic guide to guide the discussion. A topic guide as an important tool for keeping the discussion centred while encouraging participants to speak naturally and spontaneously [8]. The topics were formulated as a series of open-ended questions. The focus group discussion guide was divided into three sections. The first section elicited information on HIV and AIDS knowledge. Questions on the HIV and AIDS definition, whether HIV and AIDS mean the same, seriousness of HIV and AIDS in the community, how a person with AIDS looks like, how one gets HIV, whether HIV and AIDS can be cured and how women can protect themselves from HIV infection were asked.

The second section (B) was designed to obtain information on sexual behaviour. This included age at sexual debut, age of partner at first coitus, ever used a condom, number of sexual partners, usually uses a condom, condom use with casual and regular partners each time and last time they had sexual intercourse and initiation of condom use. The last section requested participants on how the problem of HIV and AIDS could be addressed and who in the community should be actively involved in addressing the problem of HIV and AIDS.

The FGDs were conducted with one group at a time per day. The interviews were conducted in the local dialect and were transcribed verbatim into English. The duration for the discussion was $1-1.5$ hours. 


\subsection{Data Analysis}

Data was analysed using Colaizzi's six-stage method of data analysis and representation which involved reading and rereading of each verbatim description with the aim of developing an understanding of the meaning of the data, extracting significant statements and phrases from the transcripts and formulation of meanings into clusters of themes [9]. The clusters brought together a series of clearly related themes. Six major themes were identified (see Table 1).

\subsection{Ethical Considerations}

Ethical clearance was granted by the University of Zambia Biomedical research committee and informed consent was obtained from the participants at the onset of the study. Confidentiality and anonymity were ensured by using codes and pseudonyms. The participants were informed that no incentives would be paid; the study had no risks and had the right to discontinue any time during the course of the study without incurring any negative consequences whatsoever.

\section{Results and Discussion}

To explore HIV and AIDS knowledge, participants discussed the following themes: definition of HIV and AIDS, seriousness of HIV and AIDS problem in the community, signs and symptoms of HIV and AIDS, transmission of HIV and AIDS, Cure and prevention for HIV and AIDS.

\subsection{Theme 1: Definition of HIV and AIDS}

Participants in the eight focus group discussions in both the intervention and control group areas were asked to define HIV according to their own understanding. Some participants displayed ignorance as indicated by this participant: "It is a new disease called AIDS". Other participants in both groups gave the correct response. This is reflected this response: "It is a virus that causes a disease known as AIDS".

On the other hand, several participants were not aware of the acronym HIV stands for, as pointed out by one participant: "What? HIV. I don't know what it means. I have no idea".

During the focus group discussions participants in both the intervention and control groups were also asked to define AIDS in their own understanding. Some participants thought that the word AIDS meant HIV as stated by one participant: "AIDS is the same as HIV. Yes they mean the same. They are the same". Other participants were able to define it correctly: "AIDS is a disease that one gets after being infected by HIV. It is characterised by many conditions such Tuberculosis".

Then, the young women were also asked to explain differences between the two terms (HIV and AIDS). An overwhelming majority of the young women in both the intervention and control group were able to differentiate between the two terms as indicated in the following statements:

"HIV is a virus that causes AIDS where as AIDS is a disease that comes after one gets infected with the virus".

"HIV is a virus that causes a disease called AIDS. AIDS is a disease that comes after getting the virus".

Other participants in both groups were of the view that the two acronyms had the same meaning as reflected in this statement: "We know that HIV and AIDS mean the same. It is this new disease that has come. That's what

\begin{tabular}{cc} 
Table 1. Identified themes on HIV and AIDS knowledge. \\
\hline Theme 1 & Definition of HIV and AIDS \\
Theme 2 & Seriousness of HIV and AIDS in the community \\
Theme 3 & Signs and symptoms of AIDS \\
Theme 4 & Transmission of HIV \\
Theme 5 & HIV and AIDS cure \\
Theme 6 & Prevention of HIV and AIDS \\
\hline
\end{tabular}


people say”.

A few participants in the intervention group did not know whether there were any differences as indicated by one participant: "Some of us have no clue what it means. We hear people talk but we do not really understand $i t$.

During the focus group discussions there was confusion regarding the definition of AIDS among participants in each focus group but after a lengthy debate, all participants agreed that the two acronyms did not mean the same and HIV was a virus whereas AIDS was a disease.

\section{Discussion of Definition of HIV and AIDS}

The above data suggest that some young women still lacked information on what the acronym HIV and AIDS stands for. There is need to provide them with information on this specific issue. HIV is an abbreviation for Human Immunodeficiency Virus which causes Acquired Immune Deficiency Syndrome (AIDS). HIV attacks the immune system, which is the body's defence system to fight off diseases. It destroys the cells (T4 cells) of the immune system or it reduces their ability to functioning properly. It works very slowly but eventually it destroys the infected person's immune system.

AIDS (Acquired Immunodeficiency Syndrome) is a condition caused by advanced HIV infection. It occurs when a person's immune system is weakened due to HIV infection which limits the body's natural ability to fight other infections and diseases. When these diseases and infections occur in people living with AIDS, they are called opportunistic infections [10]. The lack of understanding of the two concepts (HIV and AIDS) could be attributed to inadequate information on the subject. Only very few participants in the control group could not define AIDS correctly. Perhaps there are more HIV and AIDS educational programs being conducted in the community in this area.

\subsection{Theme 2: Seriousness of HIV and AIDS in the Community}

Focus group members in both groups acknowledged the fact that HIV and AIDS was a serious problem in their communities and that they knew people in their community who had died of AIDS as evidenced by the following responses from five participants:

"It has killed my aunt and sister. I had to take care of them when they were sick".

"It has killed a lot of people including my relatives. Lives have perished leaving many children ending in the streets".

"It is causing many deaths resulting in an increased number of orphans with no food, no school fees resulting in increased school drop outs".

"Children headed households and child labour are also on the increase because there is no one to take care of the children as their parents have died from the disease and therefore they end up working in other people's fields to survive".

"Many people are taking care of patients with AIDS and those taking care of patients become depressed and they feel helpless to watch their loved one suffer for a long time and go".

\section{Discussion of Seriousness of HIV and AIDS in the Community}

The above data suggest that participants acknowledged that HIV and AIDS was a serious disease and that it was common among the Zambian communities. This result is in agreement with [3] that reported that about two thirds (65.8\%) of adolescent females in Zambia said that they knew someone with HIV and AIDS or who had had died of HIV and AIDS.

\subsection{Theme 3: Signs and Symptoms of AIDS}

In order for the young women to avoid HIV and AIDS, they must have accurate perceptions of HIV and AIDS. When asked to describe how a person with HIV and AIDS looked like, participants in both the intervention and control groups identified symptoms such as weight loss, diarrhoea, perpetual illness, herpes zoster, persistent fever, skin rashes, loss of appetite, sores in the mouth, on the body and private parts, pallor and swollen feet. A participant had this to say: "A person who has HIV and AIDS suffers from diarrhoea very often, looses a lot of weight and is perpetually ill".

"A person with HIV and AIDS has rashes with grey skin. Even if he applies body lotion the skin looks as if he 
hasn't. Others develop herpes zoster on his/her body and have persistent fever".

"In most cases a person who has HIV and AIDS has sores in the mouth and losses appetite. He also develops skin rashes on the whole body and others have swollen feet".

"HIV and AIDS make someone's blood to finish in his or her body. Some people with HIV and AIDS have sores on the body and private parts".

Some participants stated that a person with HIV and AIDS looked pale and unhealthy with thin hair and had a persistent cough as this statement shows:

"An HIV and AIDS person has thin hair, looks unhealthy or pale; he or she is always coughing".

A few participants said that a person with HIV could look healthy as reflected in this response:

"A person with HIV can look healthy. Because you cannot tell if a person has it by looking at her or him".

\section{Discussion of Signs and Symptoms of AIDS}

The above data reveals that the young women are able to distinguish a person with HIV and AIDS from one without by the commonly known symptoms. Commonly reported symptoms were; Skin rashes, Herpes zoster, persistent cough, persistent fever, loss of weight, thin hair, loss of appetite, sores in the mouth, body sores including private parts, pallor, anaemia and swollen feet.

Although some participants in the intervention group were able to identify symptoms of HIV and AIDS, only a few of them knew that a healthy looking person can have HIV. This means that young women are lacking information on this specific matter. Therefore there is need to address this issue as quickly as possible if HIV and AIDS is to be prevented. People with HIV and AIDS may lack symptoms when they are in the sero-conversion and asymptomatic sero-positive stages. In fact, for some people with HIV, it can take 10 years or more between initial HIV infection and the diagnosis of AIDS [11]. Now with advances in treatment, this time lag between HIV infection and AIDS diagnosis may be lengthened even further. This result is contrary to CSO (2003: 9) findings that $76.8 \%$ of female adolescents in Zambia know that a healthy looking person can have HIV.

The seroconversion stage is the period when a person converts from HIV negative to HIV positive status [5]. During this time there are symptoms but a person is highly infectious because the HIV is replicating quickly without being kept in check by antibodies. Asymptomatic sero-positive stage is a period from sero-conversion to the time one begins to manifest symptoms [5]. In this stage, a person shows no symptoms of the infection.

The symptomatic stage is the phase when symptoms begin to manifest. Once symptoms begin to develop, they may include; any unexplained loss of weight lasting at least one month, diarrhoea for several weeks or more, a white coating on the tongue, enlarged or sore glands in the neck, armpit, and/or other parts of the body, a cough that persists for more than one month, persistent fever and/or night sweats and persistent vaginal yeast infections.

Full-blown AIDS stage is the phase when the immune system is weakened and the body is unable to fight off nearly all infections [12]. Multiple symptoms are a common feature during this stage. The above findings suggest that participants in both groups had some knowledge on the symptoms of HIV and AIDS.

This result is in agreement with the population based survey which revealed that young women (80\%) had knowledge about specific HIV and AIDS symptoms [13]. However, more emphasis should be placed on the fact that a healthy looking person could transmit HIV if infected.

\subsection{Theme 4: HIV Transmission}

There are various ways through which HIV is transmitted, for instance, through heterosexual contact. Prenatal transmission during pregnancy, at birth or while breastfeeding is the next significant mode of HIV transmission. Others are through contaminated blood and blood products, use of needles, sharp instruments and sexual intercourse between men.

The young women were asked to describe how HIV infection is transmitted. Most of the participants in the intervention group gave the following responses: "HIV is spread by having sex without a condom and by sharing razor blades, needle and knives which could have been contaminated with blood from an infected person. One can have, say, if you are infected and you used to shave yourself and you cut yourself then you give that to another person to use then they can get infected".

"It can pass from a mother who has it to her baby through breastfeeding. It can also be spread by contaminated blood transfusion if you go to the hospital and they give you blood". 
"One can get HIV by having many sexual partners and by putting things in the vagina that make it dry... And also by not wearing a condom when having sex".

Several participants in both the intervention and control group expressed that HIV infection is transmitted by kissing and through casual contact as indicated in the following responses:

"This disease is spread by kissing someone who has it".

"It can be spread by sharing utensils with a person who has it if you live with him or her in the same house".

\section{Discussion on HIV Transmission}

The study findings show that participants knew various ways in which HIV and AIDS is transmitted as the majority were able to mention one or two ways in which the disease is transmitted. These findings are consistent with the previous survey reports that most young people have knowledge of specific modes of transmission [14]. HIV infection is spread from one person to another through the exchange of blood or other body fluid such as semen, vaginal secretions and breast milk [11]. HIV can be transmitted through the following behaviours; sexual contact (primarily unprotected vaginal or anal intercourse) and blood and other fluids by sharing needles, intravenous (IV) drugs and drug paraphernalia, Receiving transfusions of infected blood or blood products and/or transplant of an infected organ, using contaminated skin-piercing instruments (needles, syringes, razor blades, tattoos needles or circumcision instruments), becoming injured from contaminated needles or other sharp objects (a risk mainly in health care setting), having infected blood or other body fluids splash onto mucous membranes such as eyes and transmission from mother to child, during pregnancy, during delivery and after delivery via breast milk while breastfeeding [11].

However, a few individuals in both groups expressed that HIV can be spread through kissing and by casual contact. This is a misconception and indicates that some young women are not getting access to the correct information. Evidence suggests that the disease is predominantly acquired through sexual intercourse followed by mother to child transmission in Sub-Saharan Africa and Zambia inclusive [15]. Such myths and misconceptions could be attributed to lack of knowledge on the subject. Myths and misconceptions thrive in a certain environment as a result of complex interactions between cultural beliefs and the level of literacy in a given community. Moreover, casual contact with an infected person cannot make one get the disease. This obviously contributes to the stigmatisation of those suspected or living with the virus. Therefore, there is need to design specific messages on HIV and AIDS transmission targeting young women. Misconceptions about HIV transmission through sharing a meal with an infected person were also reported by other researchers [3].

\subsection{Theme 5: HIV and AIDS Cure}

During the focus group discussions, a large number of participants in the intervention group expressed that AIDS had no cure as noted by this participant: "We have heard that this disease cannot be cured, it is a deadly disease. Once you have it you will take it your grave. You are gone”. A few participants in the same group thought that HIV infection could be cured by prayer as this participant stated: "Yes this disease can be cured if you believe in the divine power of God our creator. We have heard of Christians being healed from the disease. There is nothing impossible with the power of God".

On the other hand all the participants in the control group were of the view that AIDS had no cure as reported by one participant "There is no medicine that can cure the disease".

\section{Discussion on HIV and AIDS Cure}

From the above findings it is quite clear that most participants were aware that HIV and AIDS have no cure. The findings in this study support those of CSO (2002: 216) which found that $80 \%$ of the women in Zambia knew that AIDS is a fatal disease. Similarly surveys conducted in Cote d'Ivoire, Gabon and Mozambique with women on HIV and AIDS awareness and behaviour reported similar findings [16]. Currently there is no cure for HIV infection or AIDS but there is medical treatment in the form of antiretroviral drugs (ARVs) which slows down the replication of HIV in the body, slowing down the effects of the disease. With the combined use of the combination therapy as well as the use of drugs to prevent opportunistic infections, many people with HIV and AIDS have extended and improved the quality of their lives and delayed the progression of HIV infection to AIDS.

Although many participants knew that there was no cure for HIV and AIDS, a few still believed that HIV and 
AIDS could be cured by prayers. Spiritual healing does take place and encourages good living and feeling but prayer does not change somebody's status from positive to negative [17]. The church should encourage those who are already infected to seek scientific remedies. Therefore there is need for the HIV and AIDS prevention programmes to work together with religious organisations to change people's mindset regarding HIV and AIDS cure.

\subsection{Theme 6: HIV and AIDS Prevention}

Knowledge of ways of HIV and AIDS prevention is vital to the prevention of the scourge. Participants were asked to explain how they could protect themselves from HIV infection. Both the intervention and control group participants stated the following:

"We can protect ourselves by using a condom each time we have sex. But the best way is to abstain from it until marriage because sleeping around can be dangerous".

"We can protect ourselves by being faithful to our partners. Both men and women should have one man or one woman for life. We can also use a condom each time we have sex".

"Protection can be achieved by avoiding early marriages where young women are forced to marry older men who may have HIV and they give them the disease and also by not using the same razor blades and knives not selling sex which could be contaminated with infected blood".

\section{Conclusions}

The findings also showed that not all the young women in both groups were knowledgeable about HIV and AIDS. Many participants in both groups did not know what the acronym HIV and AIDS stood for. Moreover, many study participants in both groups were also not aware that a healthy looking person could have the virus that caused AIDS. The study has also revealed misconceptions regarding HIV transmission, for instance, some participants in both the intervention and control groups thought that HIV could be transmitted through kissing and sharing the same utensils with an infected person or living in the same house with an infected person. Although many participants knew that there was no cure for AIDS, a few thought that HIV could be healed through prayer.

Generally, the results revealed that the study participants knew that HIV and AIDS were a serious problem in the community; participants were personally affected by HIV and AIDS or knew other people who were affected. In addition, study participants in both groups had knowledge of specific signs and symptoms of HIV and AIDS. The findings also showed that the majority of the participants knew one or two modes in which HIV was transmitted, and HIV and AIDS prevention methods. However, unless young women assume responsibility for safe sex each time they had sexual intercourse and receive accurate information, HIV and AIDS will continue to spread. There is therefore need for continued community sensitization on HIV and AIDS.

\section{References}

[1] UNAIDS (2004) UNAIDS Report on the Global AIDS Epidemic. UNAIDS, Geneva.

[2] UNAIDS/WHO (2005) AIDS Epidemic Update. UNAIDS, Geneva.

[3] Central Statistical Office (2003) Zambia Sexual Behaviour Survey. Central Statistical Office, Ministry of Health and Measures Evaluation, Chapel Hill.

[4] Simwanza, A. (2005) The Post 3207: 15 Friday July 29.

[5] Pratt, R.J. (1995) HIV and AIDS: A Strategy for Nursing Care. 4th Edition, Arnold, London.

[6] Ulin, R.P., Robinson, T.E., Trolley, E.E. and McNeil, T.E. (2002) Qualitative Methods: A Field Guide for Applied Research in Sexual and Reproductive Health. Family Health International, Research Triangle Park.

[7] LoBiondo-Wood, G. and Haber, J. (2006) Nursing Research: Methods and Critical Appraisal for Evidence-Based Practice. 6th Edition, Mosby Inc., St Louis.

[8] Hogle, J., Stalker, M., and Hassig, S. (1996) Conducting Effective Focus Group Discussions. Family Health International, Arlington.

[9] Creswell, J.W. (2003) Research Design: Qualitative and Quantitative Approaches. Sage, Thousand Oaks.

[10] Center for Disease Control and Prevention (1999) Family Planning Methods and Practice: Africa. 2nd Edition, United States Department of Health and Human Services, Center for Disease Control and Prevention, National Center for 
Chronic Disease Prevention and Health Promotion, Division of Reproductive Health, Atlanta.

[11] Avert (2014) HIV Transmission Routes. www.avert.org/can-you-get-hiv.htm

[12] Ministry of Health and Central Board of Health (2002) Integrated Technical Guidelines for Frontline Health Workers. 2nd Edition, Ministry of Health and Central Board of Health, Lusaka.

[13] Central statistical Office (2002) Zambia Demographic and Health Survey: 2001-2002. Central Statistical Office, Ministry of Health (MoH) and Macro International Inc., Calverton.

[14] Raheel, H., White, F., Kadir, M.M. and Fatmi, Z. (2007) Knowledge and Beliefs of Adolescents Regarding Sexually Transmitted Infections and HIV/AIDS in a Rural District in Pakistan. Journal of Pakistan Medical Association, 1, 8-10.

[15] WHO (2002) Facts Sheets on HIV/AIDS. World Health Organization, Geneva.

[16] Brewer, D.D, Potterat, J.J, Garrett, S.B, Muth, S.Q, Roberts, J.M, Kasprzy, R.D, Montano, D.E and Darrow, W.W. (2000) Prostitution and the sex discrepancy in reported number of sexual partners. Proceedings of the National Academies of Sciences of the United States of America, 97, 12385-12388. http://dx.doi.org/10.1073/pnas.210392097

[17] Sozi, C. (2007) Its Reckless Telling People to Stop Taking ARVs. The Post No. 3994, 2. 